The lasers used were a $\mathrm{XeCl}$ laser operating at $308 \mathrm{~nm}, \tau_{\text {pulse }} \approx 30 \mathrm{~ns}$ (Lambda Physik, EMG 201 MSC), and an Nd:yttrium aluminum garnet (YAG) laser, operating at the second harmonic, $\lambda=532 \mathrm{~nm}$, $\tau_{\text {pulse }} \approx 5 \mathrm{~ns}$ (B. M. Industries, Serie 5000).

Experimental Methods: For the macroscopic mechanical actuation of the films, the laser beams were weakly focused onto the front surface of the film so that the entire surface area of the film was homogeneously irradiated (spot area: $1.5 \mathrm{~mm} \times 2.5 \mathrm{~mm}$ ). A digital camera, placed at an angle of $\sim 85^{\circ}$ to the normal to the surface, was used for monitoring the bending of the films.

In the fluorescence experiments, the UV laser beam was weakly focused almost perpendicularly onto the sample in a $1.2 \mathrm{~mm}$ diameter spot using a quartz spherical lens $(f=+500 \mathrm{~mm})$. The green laser beam was also weakly focused onto exactly the same area where the UV beam is focused, almost perpendicularly to the sample. Irradiation of the samples was performed in ambient atmosphere. The fluorescence of the stable trans MC photoproducts was probed by excitation with laser pulses of $532 \mathrm{~nm}$ of very low fluence $\left(F_{\text {laser }} \leq 4 \mathrm{~mJ} \mathrm{~cm}^{-2}\right)$. Photoproduct formation by the probe beam was negligible, and all recorded fluorescence can be assumed to derive exclusively from photoproducts formed by the preceding pump laser pulses. A relatively long delay (of the order of several seconds) between the pump and probe pulses was employed for ensuring that the fast-formed, metastable isomers had turned into the final/stable isomers. On the other hand, the monitoring of the metastable photoproducts was achieved by collecting the emission signals from the samples with zero delay with respect to the pump laser pulses.

The induced emission was collected by an optical fiber placed nearly perpendicular to the substrate and $\sim 1-2 \mathrm{~cm}$ from its surface. An $x-y$ micrometer ensured accurate positioning of the optical fiber relative to the irradiated spot. The light from the fiber was spectrally analyzed in a $20 \mathrm{~cm}$ grating spectrograph and recorded by a gated optical multichannel analyzer (OMA III system, EG\&G PARC Model 1406). A gate time value of $1 \mu$ s was applied.

Received: July 6, 2004 Final version: December 7, 2004

[1] W. H. Teh, J. K. Luo, M. A. Graham, A. Pavlov, C. G. Smith, J. Micromech. Microeng. 2003, 13, 591.

[2] L. R. Dalton, J. Phys.: Condens. Matter 2003, 15, R897.

[3] N. C. MacDonald, in Nanotechnology (Ed: G. L. Timp), Springer, New York 1999, Ch. 3.

[4] O. Lehmann, M. Stuke, Science 1995, 270, 1644.

[5] A. Y. Bobrovsky, N. I. Boiko, V. P. Shibaev, Adv. Mater. 1999, 11, 1025.

[6] O. Pieroni, A. Fissi, N. Angelini, F. Lenci, Acc. Chem. Res. 2001, 34,

[7] A. Fissi, O. Pieroni, F. Ciardelli, Biopolymers 1987, 26, 1993.

[8] B. R. Malcolm, O. Pieroni, Biopolymers 1990, 29, 1121.

[9] T. Ikeda, M. Nakano, Y. Yu, O. Tsutsumi, A. Kanazawa, Adv. Mater. 2003, 15,201

[10] Y. Yu, M. Nakano, T. Ikeda, Nature 2003, 425, 145.

[11] A. Athanassiou, K. Lakiotaki, V. Tornari, S. Georgiou, C. Fotakis, Appl. Phys. A: Mater. Sci. Process. 2002, 76, 97.

[12] H. Görner, L. S. Atabekyan, A. K. Chibisov, Chem. Phys. Lett. 1996 260,59 .

[13] N. P. Ernsting, T. Arthen-Engeland, J. Phys. Chem. 1991, 95, 5502

[14] M. Levitus, M. Talhavini, R. M. Negri, T. D. Z. Atvars, P. F. Aramendia, J. Phys. Chem. B 1997, 101, 7680.

[15] A. K. Chibisov, H. Görner, J. Photochem. Photobiol., A 1997, 105, 261.

[16] E. A. Gonzalez-De Los Santos, M. J. Lozano-Gonzalez, A. F. Johnson, J. Appl. Polym. Sci. 1999, 71, 259.

[17] H. Görner, Chem. Phys. 1997, 222, 315

[18] P. Uznanski, Synth. Met. 2000, 109, 281.

[19] N. Angelini, B. Corrias, A. Fissi, O. Pieroni, F. Lenci, Biophys. J. 1998, 74, 2610.

[20] C. Lenoble, R. S. Becker, J. Phys. Chem. 1986, 90, 62.

\section{Highly Efficient UV Organic Light-Emitting Devices Based on Bi(9,9-diarylfluorene)s**}

\author{
By Teng-Chih Chao, Yu-Ting Lin, Chen-Yu Yang, \\ Tsung Shi Hung, Hung-Chieh Chou, Chung-Chih Wu,* \\ and Ken-Tsung Wong*
}

The rapid advancement of organic light-emitting devices (OLEDs) in recent years has extended the emission wavelengths over the whole visible range and has enabled realization of full-color OLED displays. Extending the emission of OLEDs into even shorter ultraviolet wavelengths, however, has not progressed as well, although compact and efficient UV emitters would find many uses in biological/fluorescent sensors,${ }^{[1-2]}$ in full-color displays by generating blue-to-red emission through pumping luminescent materials, ${ }^{[3]}$ or in high-density information storage devices. ${ }^{[4-6]}$ In addition, wide-gap materials are also of increasing importance in triplet emitters for electrophosphorescence. ${ }^{[7-9]}$ In the few existing reports of UV OLEDs, ${ }^{[10-16]}$ emitting materials are based on either polysilanes or aromatic amines. In these reports, although the best electroluminescence (EL) efficiency obtained is near $2 \%$ (photon/electron), the emission, however, is mainly above $400 \mathrm{~nm}$, i.e., blue-violet emission. Therefore, efficient OLEDs with true UV emission (below $400 \mathrm{~nm}$ ) are still being aggressively sought.

The molecular design of amorphous organic materials capable of efficient UV emission in OLEDs is highly challenging. To achieve a short-wavelength emission, the extent of conjugation in the molecule must be confined, which in turn would usually impose constraints in molecular size. Limited $\pi$-conjugation would lead to a strong tendency to destabilize the radical cations and/or radical anions upon electrochemical oxidation and/or reduction, ${ }^{[17]}$ respectively, which is detrimental for electrical operation of devices. Furthermore, along with the usual requirements of rigidity and coplanarity in molecular geometry to obtain efficient luminescence, the limited molecular size normally renders it more difficult for the molecules to form morphologically stable and uniform amorphous thin films. Hence, an exquisite molecular design is highly desired to fully compromise the conflicting demands of $\pi$-systems

[*] Prof. C.-C. Wu, Y.-T. Lin, C.-Y. Yang Department of Electrical Engineering Graduate Institute of Electro-optical Engineering and Graduate Institute of Electronics Engineering Taipei 106 (Taiwan)

E-mail: chungwu@cc.ee.ntu.edu.tw

Prof. K.-T. Wong, T.-C. Chao, T. S. Hung, H.-C. Chou

Department of Chemistry

National Taiwan University

Taipei 106 (Taiwan)

E-mail: kenwong@ntu.edu.tw

[***] The authors gratefully acknowledge financial support from the National Science Council of Taiwan. 
with limited conjugation and dimension. As such, a few intriguing properties found for efficient blue-light-emitting ter(9,9-diarylfluorene)s may provide some hints towards these issues. ${ }^{[18]}$ It is found that while the terfluorene backbone governs the electronic, electrochemical, and photophysical properties, the peripheral aryl groups connected to the C9 carbon of the fluorene by the intrinsically stronger $\mathrm{Csp}^{3}-\mathrm{Csp}^{2}$ bonds make significant contributions to the morphological and thermal stability of the materials. ${ }^{[18,19]}$ The steric and bulky aryl substituents also help conserve the high photoluminescent (PL) quantum yields that result from the coplanar geometry of fluorenes in thin films. Therefore, it appears rational to apply a similar strategy to obtain efficient and stable UV-emitting materials by shortening the oligofluorene backbone. In this paper, we report a series of highly efficient UV-emitting materials and devices based on bi(9,9-diarylfluorene)s.

The bi(9,9-diarylfluorene)s used for this study are conveniently synthesized with reasonable isolated yields $\left(\mathbf{B 2}:{ }^{[20]} 75 \%\right.$, T2: $70 \%$, TB2: $72 \%$ ) by Pd-catalyzed Suzuki coupling reactions of 2-bromo-9,9-diarylfluorenes and the corresponding 9,9-diarylfluorene-2-boronic esters (Scheme 1). Different aryl substituents are introduced to investigate the structure-property relationship. For comparison, a model compound (E2) with ethyl substitution on $\mathrm{C} 9$ is also synthesized in a similar manner with an isolated yield of $71 \%$. These bifluorenes are fully characterized with satisfactory spectroscopic data and their purity confirmed by elemental analysis.

All three bi(9,9-diarylfluorene)s exhibit high decomposition temperatures $\left(T_{\mathrm{d}}\right.$, corresponding to a $5 \%$ weight loss by thermogravimetric analysis) over $380^{\circ} \mathrm{C}$ (Table 1). In particular, TB2 exhibits an impressive $T_{\mathrm{d}}$ of $424^{\circ} \mathrm{C}$. Apparently, the bifluorene $\mathbf{E 2}$ with peripheral alkyl groups exhibits a lower tolerance to heat with a $T_{\mathrm{d}}$ of $268^{\circ} \mathrm{C}$. Results of differential scanning calorimetry (DSC) reveal high glass-transition temperatures $\left(T_{\mathrm{g}}\right)$ of these bi(9,9-diarylfluorene) compounds, all higher than $150^{\circ} \mathrm{C}$ (Table 1$)$. As a consequence, these bi(9,9diarylfluorene)s are able to form homogeneous and stable amorphous films by thermal evaporation. In contrast, no $T_{\mathrm{g}}$ is detectable for E2, and the vacuum-deposited E2 films are crystalline, indicating that it is a highly crystalline material. Furthermore, it is of note that the molecular design of truly amorphous materials can be achieved by introducing chiral centers in close proximity of the conjugated chromophore backbone, as revealed by comparing DSC traces of $\mathbf{B 2}$ and TB2 (Fig. 1). B2, which possesses a more rigid structural feature, exhibits a distinct crystallization temperature $\left(T_{\mathrm{c}}\right.$ : $\left.242{ }^{\circ} \mathrm{C}\right)$ and melting temperature $\left(T_{\mathrm{m}}: 352^{\circ} \mathrm{C}\right)$. Meanwhile, TB2, which is isolated as a diastereomeric mixture, shows no

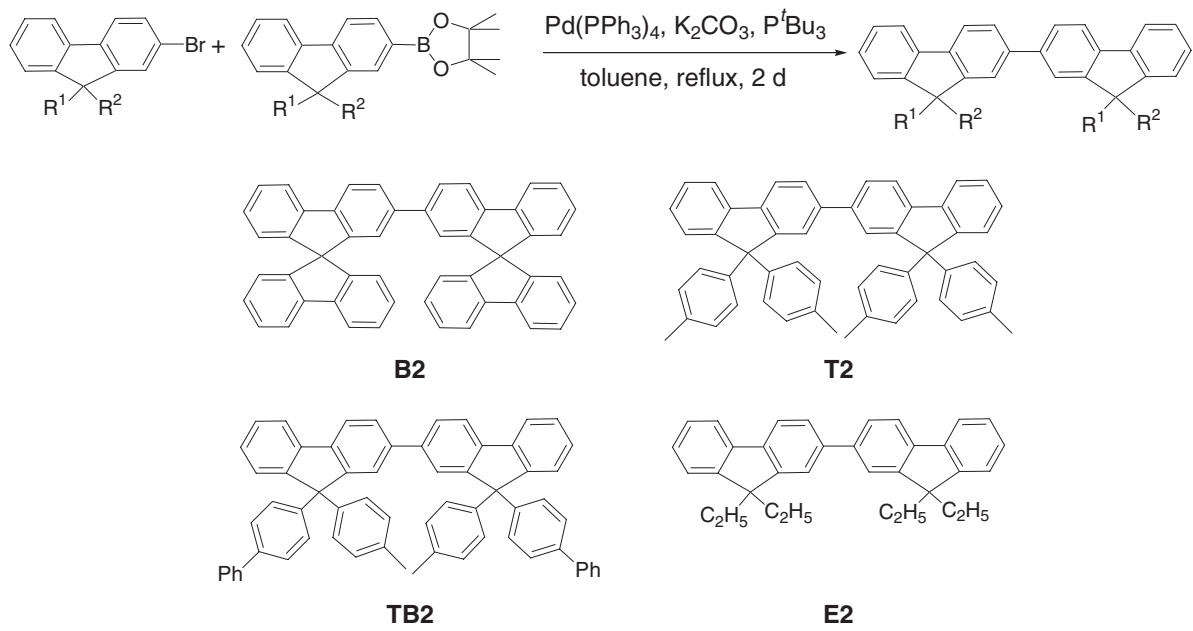

Scheme 1. Synthesis and structures of bifluorenes.

Table 1. Summary of physical properties of bifluorenes.

\begin{tabular}{ccccccccc}
\hline Sample & $\begin{array}{c}T_{\mathrm{d}}[\mathrm{a}] \\
{\left[{ }^{\circ} \mathrm{C}\right]}\end{array}$ & $\begin{array}{c}T_{\mathrm{g}}[\mathrm{b}] \\
{\left[{ }^{\circ} \mathrm{C}\right]}\end{array}$ & $\begin{array}{c}E_{1 / 2} \text { oxid./red. }[\mathrm{c}] \\
{[\mathrm{V}]}\end{array}$ & $\begin{array}{c}\lambda_{\max }\left(\lambda_{\text {onset }}[\mathrm{d}]\right. \\
{[\mathrm{nm}]}\end{array}$ & $\begin{array}{c}\lambda_{\text {max,sol }}, \mathrm{PL}[\mathrm{e}] \\
{[\mathrm{nm}]}\end{array}$ & $\begin{array}{c}\lambda_{\text {max,film, }}, \mathrm{PL}[\mathrm{f}] \\
{[\mathrm{nm}]}\end{array}$ & $\begin{array}{c}\mathrm{QY} \\
\text { sol }\end{array}$ & $\begin{array}{c}\mathrm{Q}] \\
\text { film }[\mathrm{h}]\end{array}$ \\
\hline B2 & 382 & 174 & $1.44 /-2.15$ & $334(375)[\mathrm{i}]$ & 364,381 & 374,392 & 0.70 & 0.66 \\
T2 & 385 & 153 & $1.42 /-2.11$ & $334(375)$ & 368,384 & 374,392 & 0.70 & 0.63 \\
TB2 & 424 & 169 & $1.46 /-2.14$ & $334(375)$ & 368,389 & 374,392 & 0.70 & 0.57 \\
E2 & 268 & $-[\mathrm{j}]$ & $1.36 /-2.31$ & $330(369)[\mathrm{k}]$ & 365,384 & $-[\mathrm{l}]$ & 0.60 & $-[\mathrm{l}]$ \\
\hline
\end{tabular}

[a] Temperature corresponding to a $5 \%$ weight-loss upon heating $\left(20^{\circ} \mathrm{C} \mathrm{min}^{-1}\right)$ under $\mathrm{N}_{2}$. [b] Recorded from heating $\left(10^{\circ} \mathrm{C} \mathrm{min}{ }^{-1}\right)$ a liquid nitrogenquenched melt-sample by DSC. [c] $\vee$ vs. Ag/AgCl. [d] First absorption peak and absorption onset in thin films. [e] PL peaks in solutions $\left(1 \times 10^{-4} \mathrm{M}\right.$ in $\left.\mathrm{CHCl}_{3}\right)$. [f] PL peaks in films. [g] PL quantum yield in solution $\left(1 \times 10^{-4} \mathrm{M}\right.$ in $\left.\mathrm{CHCl}_{3}\right)$. [h] PL quantum yield in thin films. [i] Also shows an absorption peak at $312 \mathrm{~nm}$. [j] No $T_{\mathrm{g}}$ detectable. Only exhibited a distinct melting point $\left(T_{\mathrm{m}}\right)$ of $213^{\circ} \mathrm{C}$. [k] In dilute $\mathrm{CHCl}_{3}$ solution (no homogeneous thin films available). [l] No homogeneous thin films available. 


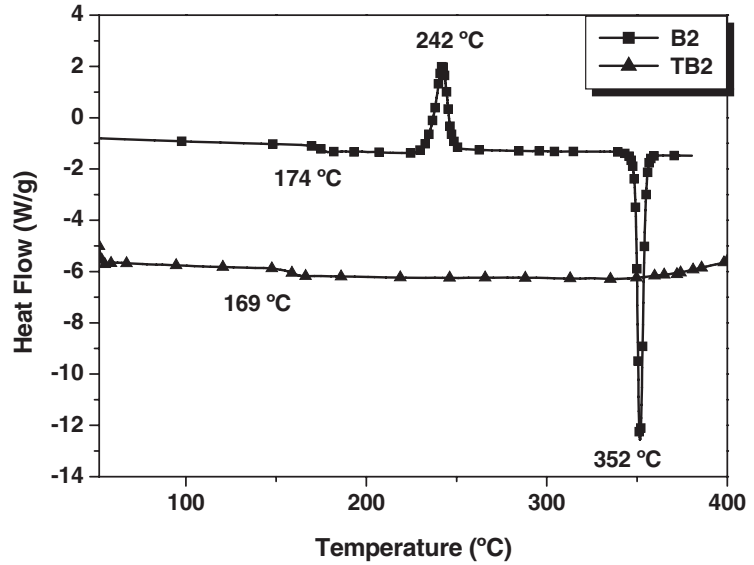

Figure 1. A comparison of DSC traces of B2 and TB2.

further phase transition upon heating above its $T_{\mathrm{g}}\left(169^{\circ} \mathrm{C}\right)$ up to $350^{\circ} \mathrm{C}$. These results indicate that even for conjugated oligomers as short as two repeating units, the judicious introduction of peripheral aryl substituents gives the molecules surprising morphological stability and resistance to thermal decomposition.

The electrochemical properties of the bifluorenes were investigated by cyclic voltammetry $(\mathrm{CV})$. Figure 2 shows the cyclic voltammogram of $\mathbf{B 2}$ as an example. A reversible reduction potential is evident at a value of $E_{1 / 2}$ of $-2.15 \mathrm{~V}$ (vs.

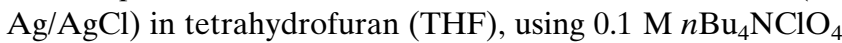
as the supporting electrolyte and a glassy carbon electrode as the working electrode. In $\mathrm{CH}_{2} \mathrm{Cl}_{2}$, using $0.1 \mathrm{M} \mathrm{nBu}_{4} \mathrm{NPF}_{6}$ as the supporting electrolyte, a reversible oxidation process $\left[E_{1 / 2}=1.44 \mathrm{~V}\right.$ (vs. $\left.\left.\mathrm{Ag} / \mathrm{AgCl}\right)\right]$ is observed. Similar CV results are obtained for all bifluorenes (Table 1). E2 exhibits a slightly lower oxidation potential and higher reduction potential than other bifluorenes, which may be attributed to the higher electron-donating ability of the ethyl substituent. These electrochemical results indicate that the electrogenerated radical ions of bifluorenes are stable, and that the coplanar character of the fluorene moieties has a beneficial effect

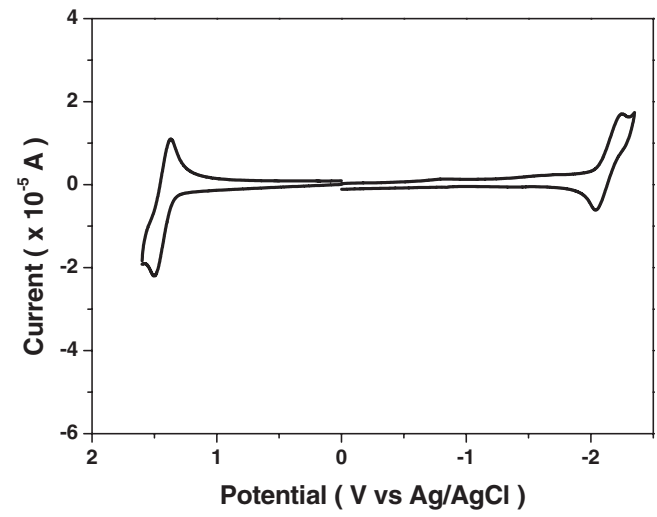

Figure 2. Cyclic voltammogram of B2, see the text for experimental details. on the reversibility of electrochemical processes. In addition, the structural variety of the peripheral C9 aryl substituents has a weak effect on electrochemical properties.

The photophysical properties (absorption spectra, photoluminescent (PL) spectra, and PL quantum yields) of the bifluorenes are summarized in Table 1. Thin-film PL of the bi(9,9-diarylfluorene)s shows strong ultraviolet (UV) emission with the first two prominent peaks below $400 \mathrm{~nm}$. Very high PL quantum yields of $>57 \%$ are observed in thin films of bi(9,9-diarylfluorene)s, which are unusual for organic UV emitters and indicate the effectiveness of the sterically bulky C9 aryl substituents in blocking the quenching processes due to intermolecular interactions. The photophysical results in Table 1 clearly indicate that the properties of the electronic transitions are mainly governed by the central bifluorene backbones and are rather intact with different aryl substituents on the C9 carbon. The tetrahedral C9 carbon thus serves as an effective insulating spacer between the central conjugated backbone and the aryl substituents. These characteristics give one much freedom in molecular design to tune various properties of the oligofluorene-based materials by varying the C9 substituents.

These efficient bi(9,9-diarylfluorene)s have been a subject of electroluminescent (EL) studies. The devices were fabricated on glass substrates with the typical structure of multiple organic layers sandwiched between the bottom indium tin oxide (ITO) anode and the top metal cathode (Al). The device structure used is ITO/PEDT:PSS $(\approx 300 \AA) / T C T A$ (400 A)/bifluorene derivative B2 (device A), T2 (device B), or TB2 (device C) (300 $)$ )/TPBI $(300 \AA) / \mathrm{LiF} \quad(5 \AA) / \mathrm{Al}$ (1500 ̊), where the conducting polymer polyethylene dioxythiophene/polystyrene sulfonate (PEDT:PSS) was used as the hole-injection layer, 4,4',4"-tri( $N$-carbazolyl)triphenylamine (TCTA) was the hole-transport layer, 2,2',2"-(1,3,5-benzenetriyl)tris[1-phenyl- $H$-benzimidazole] (TPBI) was the electron-transport layer, and $5 \AA \mathrm{LiF}$ was the electron-injection layer.

Figure 3 shows the EL spectra of the B2, T2, and TB2 devices in comparison with their thin-film PL spectra. These devices exhibit UV EL similar to the PL spectra of bifluorenes, highlighting the EL emission from the bifluorenes and the effectiveness of the present device structure in injecting both electrons and holes into the bifluorenes. Among them, B2 (device A) shows the most prominent emission below $400 \mathrm{~nm}$ (in the UV region) with two distinct EL peaks at 374 and $392 \mathrm{~nm}$. OLEDs containing large energy-gap emitters would usually lead to a greater difficulty in carrier injection and, consequently, a higher device voltage. Here, in spite of the large energy gaps of the bifluorenes, these devices show a rather low turn-on voltage of $\approx 2.5 \mathrm{~V}$ (defined as the voltage where EL emission becomes detectable) and low operation voltage $\left(100 \mathrm{~cd} \mathrm{~m}^{-2}\right.$ at $\approx 7 \mathrm{~V}, 1000 \mathrm{~cd} \mathrm{~m}^{-2}$ at $\left.\approx 8.5 \mathrm{~V}\right)$, as shown in Figure 4 . These may, in part, be attributed to superior bipolar carrier-transport properties of the present bi(9,9-diarylfluorene)s (with hole and electron mobilities of $\approx 10^{-3} \mathrm{~cm}^{2} \mathrm{~V}^{-1} \mathrm{~s}^{-1}$ ). ${ }^{[21]} \mathrm{A}$ high EL external quantum efficiency of $2.7-3.6 \%$ (photon/ 
(a)

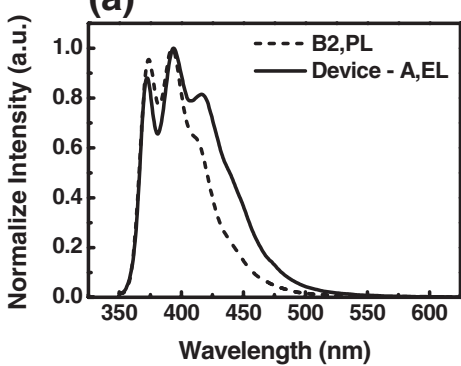

(b)

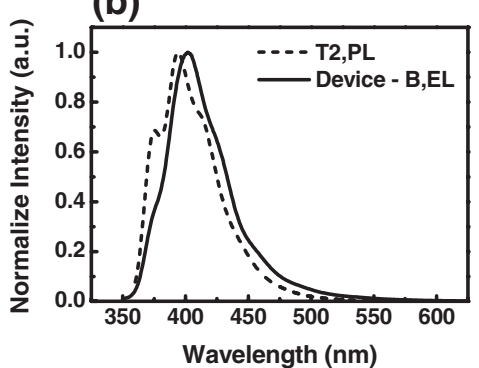

(c)



Figure 3. EL spectra of devices in comparison with thin-film PL spectra: a) B2, b) T2, and c) TB2.

(a)

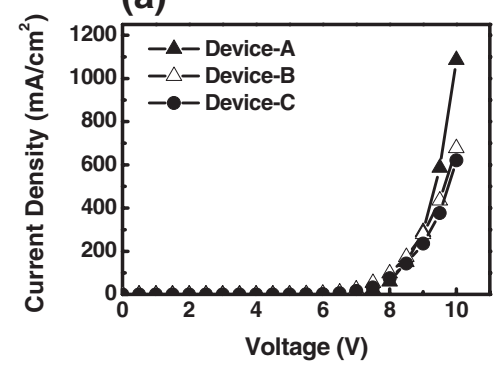

(b)



(c)

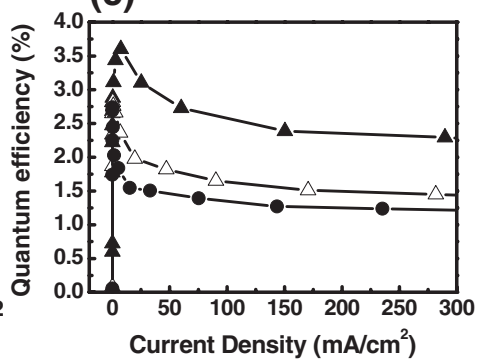

Figure 4. Current-voltage-brightness characteristics of the three devices: a) current vs. voltage characteristics, b) brightness vs. voltage characteristics, c) external EL quantum efficiencies vs. current characteristics.

electron) and high brightness were observed (Fig. 4), of which the device using $\mathbf{B 2}$ gives the highest efficiency of $3.6 \%$ and the highest brightness of nearly $5000 \mathrm{~cd} \mathrm{~m}^{-2}$. The device characteristics are summarized in Table 2.

Considering the low visibility of UV and near-UV emission, these are very high efficiencies and brightnesses and represent the highest UV EL efficiencies and brightnesses for UV OLEDs in comparison with previously reported results. ${ }^{[10-16]}$ Such high EL efficiencies are consistent with high thin-film PL quantum yields of the present bifluorene compounds. It should also be emphasized that such EL performances are achieved with neat emitting layers without emissive dopants. The high EL efficiencies and low device voltage also indicate rather effective and balanced hole/electron injection into the large-energy-gap UV-emitting bifluorenes in the present device structure. The fact that both carrier-transport layers, TCTA and TPBI, have larger energy gaps than the bifluorenes perhaps also contributes to the confinement of carriers and excitons in the bifluorenes and, consequently, high EL efficiencies. Finally, Figure 5 shows a photograph, taken under

Table 2. Summary of device performances.

\begin{tabular}{ccccccc}
\hline Device & $\begin{array}{c}\lambda_{\max }, \mathrm{PL} \\
{[\mathrm{nm}]}\end{array}$ & $\begin{array}{c}\lambda_{\max }, \mathrm{EL} \\
{[\mathrm{nm}]}\end{array}$ & $\begin{array}{c}\eta_{\text {ext }} \\
{\left[\%, 100 \mathrm{~cd} \mathrm{~cm}^{-2}\right]}\end{array}$ & $\begin{array}{c}\eta_{\max , \text { ext }} \\
{[\%]}\end{array}$ & $\begin{array}{c}\text { Turn-on voltage } \\
{[\mathrm{V}]}\end{array}$ & $\begin{array}{c}L_{\max } \\
{\left[\mathrm{cd} \mathrm{m}^{-2}, \mathrm{~V}\right]}\end{array}$ \\
\hline A & 374,392 & 374,392 & 3.6 & 3.6 & 2.5 & 4890,11 \\
B & 374,392 & 402 & 1.9 & 2.8 & 2.5 & 3183,11 \\
C & 374,392 & 374,396 & 1.9 & 2.7 & 2.5 & 2894,11 \\
\hline
\end{tabular}

a normal lighting environment, of strong red, green, and blue emission from corresponding fluorescent dye solutions pumped by a UV OLED of this work, demonstrating strong UV emission from the UV OLED and its pumping capability.

In conclusion, a series of highly efficient UV emitters based on bi(9,9-diaryfluorene)s has been synthesized and fully characterized. The promising physical properties of these novel materials, including high quantum yields of UV emission, high morphological and thermal stability, and reversible electrochemical behaviors, can be distinctly ascribed to the coplanar fluorene skeleton as well as the introduction of aryl groups as bulky peripheral substituents. These intriguing materials demonstrate the first example of pure aromatic hydrocarbons as highly potential UV emitters in OLED applications.

\section{Experimental}

Synthesis: To a solution of 2-bromo-9,9-diarylfluorene (1.1 mmol), 2-(4,4,5,5-tetramethyl-[1,3,2]-dioxaborolan-2-yl)-9,9-diarylfluorene $(1 \mathrm{mmol})$, and $\mathrm{Pd}\left(\mathrm{PPh}_{3}\right)_{4}(0.05 \mathrm{mmol})$ in toluene, were added aqueous $2 \mathrm{M} \mathrm{K}_{2} \mathrm{CO}_{3}(2 \mathrm{mmol})$ and $0.05 \mathrm{M} \mathrm{P}\left({ }^{t} \mathrm{Bu}\right)_{3}$ $(0.1 \mathrm{mmol})$. The solution was refluxed with stirring for $48 \mathrm{~h}$. The mixture was then poured into water and extracted with chloroform. The organic extracts were washed with brine and dried over magnesium sulfate. The solvent was removed by rotary evaporation, and the residue was purified by column chromatography $\left(\mathrm{SiO}_{2}, \mathrm{CHCl}_{3} /\right.$ hexanes $=1 / 4)$ to provide the desired product as a white solid. 


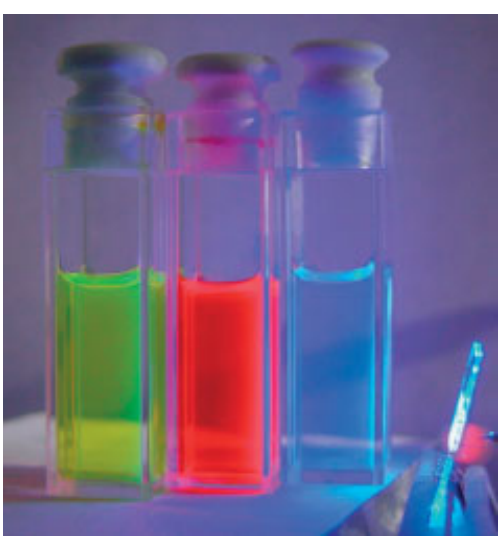

Figure 5. A UV OLED pumping solutions of red, green, and blue fluorescent dyes.

Compound Characterization: B2: $\mathrm{mp} 352^{\circ} \mathrm{C}$ (DSC); IR (KBr) $v$ 3072, 1607, 1454, 1401, 1255, 1096, 871, 831, 751, 725, $625 \mathrm{~cm}^{-1} ;{ }^{1} \mathrm{H}$ NMR $\left(\mathrm{CDCl}_{3}, 400 \mathrm{MHz}\right) \delta 7.83(\mathrm{~d}, J=7.2 \mathrm{~Hz}, 2 \mathrm{H}), 7.78(\mathrm{~d}$, $J=7.6 \mathrm{~Hz}, 1 \mathrm{H}), 7.73(\mathrm{~d}, J=8 \mathrm{~Hz}, 1 \mathrm{H}), 7.37-7.30(\mathrm{~m}, 4 \mathrm{H}), 7.10-7.04$ $(\mathrm{m}, 3 \mathrm{H}), 6.86(\mathrm{~d}, J=1.2 \mathrm{~Hz}, 1 \mathrm{H}), 6.71(\mathrm{~d}, J=7.6 \mathrm{~Hz}, 2 \mathrm{H}), 6.65(\mathrm{~d}$, $J=7.2 \mathrm{~Hz}, 1 \mathrm{H}) ;{ }^{13} \mathrm{C} \mathrm{NMR}\left(\mathrm{CDCl}_{3}, 100 \mathrm{MHz}\right) \delta 149.0,148.9,148.5$, 141.6, 141.0, 140.8, 127.7, 127.1, 127.6, 127.5, 127.0, 124.0, 123.8, 122.5, 119.9, 66.0; Mass spectrometry (MS) $\left(\mathrm{m} / z, \mathrm{FAB}^{+}\right) 630$ (100\%); highresolution MS (HRMS) $\left(\mathrm{M}^{+}, \mathrm{FAB}^{+}\right)$Calcd. for $\mathrm{C}_{50} \mathrm{H}_{30}$ 630.2347, Found 630.2342. Anal. Calcd. for $\mathrm{C}_{50} \mathrm{H}_{30}$ : C 95.21, H 4.79. Found: $\mathrm{C}$ 95.52, H 4.67 .

T2: $\operatorname{mp} 348^{\circ} \mathrm{C}$ (DSC); IR (KBr) v 3032, 2919, 2866, 1912, 1799, 1607, 1514, 1441, 1189, 1116, 1023, 891, 804, 751, 586, $506 \mathrm{~cm}^{-1} ;{ }^{1} \mathrm{H}$ $\mathrm{NMR}\left(\mathrm{CDCl}_{3}, 400 \mathrm{MHz}\right) \delta 7.74(\mathrm{~d}, J=7.6 \mathrm{~Hz}, 4 \mathrm{H}), 7.56(\mathrm{~d}$, $J=1.2 \mathrm{~Hz}, 2 \mathrm{H}), 7.52(\mathrm{dd}, J=7.6,1.2 \mathrm{~Hz}, 2 \mathrm{H}), 7.32-7.39(\mathrm{~m}, 4 \mathrm{H}), 7.25$ $(\mathrm{td}, J=7.2,1.2 \mathrm{~Hz}, 2 \mathrm{H}), 7.11(\mathrm{~d}, J=8 \mathrm{~Hz}, 8 \mathrm{H}), 7.02(\mathrm{~d}, J=8 \mathrm{~Hz}, 8 \mathrm{H})$, $2.29(\mathrm{~s}, 12 \mathrm{H}) ;{ }^{13} \mathrm{C} \mathrm{NMR}\left(\mathrm{CDCl}_{3}, 100 \mathrm{MHz}\right) \delta 151.9,151.6,142.8$, 140.6, 139.6, 139.1, 136.0, 128.8, 127.9, 127.5, 127.2, 126.5, 126.0, 124.5, 120.1, 120.0, 65.0, 21.1; MS ( $\left.m / z, \mathrm{FAB}^{+}\right) 690$ (7), 307 (100); HRMS $\left(\mathrm{M}^{+}, \mathrm{FAB}^{+}\right)$Calcd. for $\mathrm{C}_{54} \mathrm{H}_{42}$ 690.3287, Found 690.3285. Anal. Calcd. for $\mathrm{C}_{54} \mathrm{H}_{42}$ : C 93.87, $\mathrm{H}$ 6.13. Found: C 93.95, H 6.02.

TB2: ${ }^{1} \mathrm{H}$ NMR $\left(\mathrm{CDCl}_{3}, 400 \mathrm{MHz}\right) \delta 7.79(\mathrm{~d}, J=4 \mathrm{~Hz}, 1 \mathrm{H}), 7.77$ (d, $J=2.4 \mathrm{~Hz}, 1 \mathrm{H}), 7.63(\mathrm{~d}, J=1.2 \mathrm{~Hz}, 1 \mathrm{H}), 7.57(\mathrm{dt}, J=8,2 \mathrm{~Hz}, 1 \mathrm{H})$, $7.52-7.54(\mathrm{~m}, 2 \mathrm{H}), 7.35-7.45(\mathrm{~m}, 6 \mathrm{H}), 7.28-7.32(\mathrm{~m}, 4 \mathrm{H}), 7.16(\mathrm{~d}$, $J=8 \mathrm{~Hz}, 2 \mathrm{H}), 7.05(\mathrm{dd}, J=8.2 \mathrm{~Hz}, 2 \mathrm{H}), 2.30(\mathrm{~d}, J=4.8 \mathrm{~Hz}, 3 \mathrm{H}) ;{ }^{13} \mathrm{C}$ NMR $\left(\mathrm{CDCl}_{3}, 100 \mathrm{MHz}\right) \delta 151.7,151.4,144.9,142.6,140.7,140.6$, $140.5,139.6,139.3,139.2,136.2,128.9,128.8,128.5,128.4,128.3,127.9$, $127.6,127.4,127.3,127.0,126.8,126.7,126.6,126.0,124.6,124.5,120.2$, 120.1, 65.0, 21.1; MS ( $\left.m / z, \mathrm{FAB}^{+}\right) 814$ (100); HRMS $\left(\mathrm{M}^{+}, \mathrm{FAB}^{+}\right)$ Calcd. for $\mathrm{C}_{64} \mathrm{H}_{46} 814.3600$, Found 814.3602; Anal. Calcd. for $\mathrm{C}_{64} \mathrm{H}_{46}$ : C 94.31, H 5.69. Found: C 94.31, H 5.47.

E2: $\operatorname{mp} 213^{\circ} \mathrm{C}(\mathrm{DSC})$; IR (KBr) $v 744,1454,2853,2919,2972 \mathrm{~cm}^{-1}$; ${ }^{1} \mathrm{H} \mathrm{NMR}\left(\mathrm{CDCl}_{3}, 400 \mathrm{MHz}\right) \delta 0.42(\mathrm{t}, J=7.2 \mathrm{~Hz}, 12 \mathrm{H}), 2.09-2.16(\mathrm{~m}$, $8 \mathrm{H}), 7.35-7.39(\mathrm{~m}, 6 \mathrm{H}), 7.62(\mathrm{~s}, 2 \mathrm{H}), 7.67(\mathrm{~d}, J=8.0 \mathrm{~Hz}, 2 \mathrm{H}), 7.76(\mathrm{~d}$, $J=8.0 \mathrm{~Hz}, 2 \mathrm{H}), 7.80(\mathrm{~d}, J=8.0 \mathrm{~Hz}, 2 \mathrm{H}) ;{ }^{13} \mathrm{C} \mathrm{NMR}\left(\mathrm{CDCl}_{3}, 100 \mathrm{MHz}\right)$ $\delta 8.6,32.8,56.2,119.7,119.8,121.4,122.9,126.1,126.8,126.9,140.5$, 140.7, 141.2, 150.1, 150.6; MS ( $\mathrm{m} / \mathrm{z}, \mathrm{FAB}) 442.2$ (75\%) ; Anal. Calcd. for $\mathrm{C}_{34} \mathrm{H}_{34}$ : C 92.26, H 7.74. Found: C 92.29, H 7.87.

$P L$ and EL Characterization: The photoluminescence (PL) quantum yields of organic thin films deposited on quartz substrates were determined using a calibrated integrating sphere coupled to a chargecoupled device (CCD) spectragraph [22]. The $325 \mathrm{~nm}$ line of the $\mathrm{He}-$ $\mathrm{Cd}$ laser was used to excite samples placed in the calibrated integrating sphere. By comparing the spectroscopic intensities of the excitation laser and the PL emission, the PL quantum yields of the organic thin films were determined.

OLEDs were fabricated on the ITO-coated glass substrates with multiple organic layers sandwiched between the transparent bottom
ITO anode and the top metal cathode. The PEDT:PSS layer was prepared by spin coating, and other material layers were deposited by vacuum evaporation in a vacuum chamber with a base pressure of $<10^{-6}$ torr. The deposition rate of organic layers was maintained at about $0.2 \mathrm{~nm} \mathrm{~s}^{-1}$ and all organic compounds of small molecular weight were purified by sublimation before use. The active area of the device is $2 \mathrm{~mm} \times 2 \mathrm{~mm}$, as defined by the shadow mask for cathode deposition.

The current-voltage-brightness (I-V-L) characterization of the lightemitting devices was performed with a source-measurement unit (SMU) and an Si photodiode calibrated with Photo Research PR650. EL spectra of the devices were collected by a calibrated CCD spectragraph.

Received: September 9, 2004 Final version: December 12, 2004

[1] Y. Kostov, C. R. Albano, G. Rao, Biotechnol. Bioeng. 2000, 70, 473.

[2] J. Sipior, G. M. Carter, J. R. Lakowicz, G. Rao, Rev. Sci. Instrum. 1997, 68, 2666.

[3] C. W. Tang, D. J. Williams, J. C. Chang, US. Patent $5249870,1994$.

[4] H. van Santen, J. H. M. Neijzen, Jpn. J. Appl. Phys., Part 1 2003, 42, 1110.

[5] J. Hellmig, A. V. Mijiritskii, H. J. Borg, K. Musialkova, P. Vromans, Jpn. J. Appl. Phys., Part 1 2003, 42, 848.

[6] Y. Sabi, S. Tamada, T. Iwamura, M. Oyamada, F. Bruder, R. Oser, H. Berneth, K. Hassenruck, Jpn. J. Appl. Phys. Part 1 2003, 42, 1056.

[7] R. J. Holmes, S. R. Forrest, Y.-J. Tung, R. C. Kwong, J. J. Brown, S. Garon, M. E. Thompson, Appl. Phys. Lett. 2003, 82, 2422.

[8] R. J. Holmes, B. W. D'Andrade, S. R. Forrest, X. Ren, J. Li, M. E. Thompson, Appl. Phys. Lett. 2003, 83, 3818.

[9] G. T. Lei, L. D. Wang, L. Duan, J. H. Wang, Y. Qiu, Synth. Met. 2004, 144, 249.

[10] L. Zou, V. Savvate'ev, J. Booher, C.-H. Kim, J. Shinar, Appl. Phys. Lett. 2001, 79, 2282.

[11] K. Okumoto, Y. Shirota, Appl. Phys. Lett. 2001, 79, 1231.

[12] C. F. Qiu, L. D. Wang, H. Y. Chen, M. Wong, H. S. Kwok, Appl. Phys. Lett. 2001, 79, 2276

[13] M. Kinoshita, H. Kita, Y. Shirota, Adv. Funct. Mater. 2002, 12, 780.

[14] K. Okumoto, Y. Shirota, Chem. Mater. 2003, 15, 699.

[15] C-H. Yuan, S. Hoshino, S. Toyoda, H. Suzuki, M. Fujiki, N. Matsumoto, Appl. Phys. Lett. 1997, 71, 3326.

[16] S. Hoshino, K. Ebata, K. Furukawa, J. Appl. Phys. 2000, 87, 1968.

[17] K.-T. Wong, C-F. Wang, C. H. Chou, Y. O. Su, G-H. Lee, S.-M. Peng, Org. Lett. 2002, 4, 4439.

[18] a) K.-T. Wong, Y.-Y. Chien, R.-T. Chen, C.-F. Wang, Y.-T. Lin, H.-H. Chiang, P.-Y. Hsieh, C.-C. Wu, C. H. Chou, Y. O. Su, G.-H. Lee, S.-M. Peng, J. Am. Chem. Soc. 2002, 124, 11576. b) C.-C. Wu, Y.-T. Lin, K.-T. Wong, R.-T. Chen, Y.-Y. Chien, Adv. Mater. 2004, 16, 61.

[19] C.-C. Wu, T.-L. Liu, W.-Y. Hung, Y.-T. Lin, K.-T. Wong, R.-T. Chen, Y.-M. Chen, Y.-Y. Chien, J. Am. Chem. Soc. 2003, 125, 3710.

[20] For more 9,9'-spirobifluorene derivatives: a) N. Johansson, J. Salbeck, J. Bauer, F. Weissoertel, P. Broems, A. Andersson, W. R. Salaneck, Adv. Mater. 1998, 10, 1136. b) T. Spehr, R. Pudzich, T. Fuhrmann, J. Salbeck, Org. Elec. 2003, 4, 61. c) D. Katsis, Y. H. Geng, J. J. Ou, S. W. Culligan, A. Trajkovska, S. H. Chen, L. J. Rothberg, Chem. Mater. 2002, 14, 1332. d) Y. Geng, D. Katsis, S. W. Culligan, J. J. Ou, S. H. Chen, L. J. Rothberg, Chem. Mater. 2002, 14, 463.

[21] C.-C. Wu, T.-L. Liu, Y.-T. Lin, W.-Y. Hung, K.-T. Wong, T.-C. Chao, T.-S. Hung, Y.-M. Chen, Appl. Phys. Lett. 2004, 85, 1173.

[22] N. C. Greenham, I. D. W. Samuel, G. R. Hayes, R. T. Phillips, Y. A. R. R. Kessener, S. C. Moratti, A. B. Holmes, R. H. Friend, Chem. Phys. Lett. 1995, 241, 89. 